\title{
Interactions between Oppositely Charged Polypeptides
}

\author{
Akio Nakajima, Katsuro Shinoda, Toshio Hayashi, \\ and Hiroko SATo \\ Department of Polymer Chemistry, Kyoto University, \\ Sakyo-ku, Kyoto 606, Japan.
}

(Received April 26, 1975)

\begin{abstract}
Conformation-directing interactions between poly(L-or poly(D-glutamic acid)) (PLG or PDG) and poly-L-lysine (PLL) in aqueous media were investigated as functions of $\mathrm{pH}$ by using the optical rotatory dispersion and circular dichroism spectroscopies. The results indicate that at $\mathrm{pH}<4 \mathrm{PLL}$ molecules surround the core of the right-handed $\alpha$-helix of PLG, and at $\mathrm{pH}$ about 7, the polyelectrolyte complex formed may be in a scramble-salt form, whereas at $\mathrm{pH}>8$, complexes of PLG-PLL are in a form close to $\beta$-structure. On the other hand, with PDG-PLL systems, in the low $\mathrm{pH}$ region, the left-handed $\alpha$-helical structure of PDG is markedly disrupted by the presence of PLL, and in the high $\mathrm{pH}$ region, the complexes may be in a form of a scramble-salt aggregate composed of $\beta$-structures.

KEY WORDS Polyelectrolyte Complex / Polypeptide / Poly(Lglutamic acid) / Poly(D-glutamic acid) / Poly-L-Lysine / Conformations / Optical Rotatory Dispersion / Circular Dischroism /
\end{abstract}

Interactions between polyelectrolytes carrying opposite charges in aqueous media lead to the formation of polyelectrolyte complexes. The study of such complexes may be traced to the work of Bungenberg de Jong and coworkers, ${ }^{1}$ who interpreted the ionic interactions in water between naturally occuring weak polyelectrolytes, gelatin and gum arabic, under changes of ionic strength, temperature, $\mathrm{pH}$, etc., as a kind of phase separation referred to the complex coacervation.

In previous works, we have investigated the complex coacervation with synthetic polyelectrolytes, i.e., partly aminoacetalyzed poly(vinyl alcohol) and partly sulfated poly(vinyl alcohol), ${ }^{2,3}$ and further discussed the effects of chain conformations of component polymers on the complex formation elsewhere. ${ }^{4,5}$

Polypeptides are characteristic in what chain conformations, such as $\alpha$-helix, $\beta$-structure, and random coil, they can take in solution, in accordance with the surrounding conditions. Further, the $\alpha$-helix can be in a left-or righthanded screw sense depending on the configurations of the backbone chains and the nature of the side chains. Accordingly, when an ionized polypeptide is reacted with an oppositely charged polyelectrolyte, the conformational change in the component polymers may be accompanied by the complex formation depending upon circumstances. Such conformation-directing interactions of polypeptides have been investigated by using polysaccharides ${ }^{6-9}$ and vinyl polymers ${ }^{10,11}$ as the partner polyelectrolytes.

Conformations of ionizable polypeptides in solutions have been extensively investigated. However, very little has been reported ${ }^{12,13}$ about the interactions between oppositely charged polypeptides. Noguchi, et al., ${ }^{12}$ examined the $\mathrm{X}$-ray diagrams and solubilities of $\mathrm{L}-\mathrm{L}$ and D-L salts between poly(glutamic acid) and polylysine, and suggested that the $\mathrm{L}-\mathrm{L}$ salt might have a helical structure with salt-bridges between two oppositely charged molecules in water, whereas the $\mathrm{D}-\mathrm{L}$ salt might assume a less regular structure having salt-bridges among many molecules. On the other hand, Hammes and Schullery $^{13}$ suggested that poly(L-glutamic acid) and poly-L-lysine formed a $\beta$-pleated sheet structure with $1: 1$ stoichiometry at $\mathrm{pH} 4$ and 7 in aqueous $0.01 M \mathrm{NaF}$, while no appreciable interaction was detected at $\mathrm{pH} 11$.

The purpose of this work is to elucidate the conformation-directing interactions between 
poly(glutamic acid) and polylysine in aqueous media as a function of $\mathrm{pH}$ by using the optical rotatory dispersion and circular dichroism spectroscopies. The systems investigated are poly(L-glutamic acid)-poly-L-lysine, and poly(Dglutamic acid)-poly-L-lysine systems. A righthanded $\alpha$-helix is known to be stable for both poly(L-glutamic acid) and poly-L-lysine, whereas the left-handed $\alpha$-helix is stable for $\operatorname{poly}(D-$ glutamic acid).

\section{EXPERIMENTAL}

\section{Materials}

Poly(L-glutamic acid) (PLG) and poly(Dglutamic acid) (PDG), and poly-L-lysine (PLL), respectively, were prepared from poly $(\gamma$-benzylL-glutamate) (PBLG) and poly( $\gamma$-benzyl-D-glutamate(PBDG) by debenzylation, and from poly (carbobenzyloxy-L-lysine) (PCBLL) by decarbobenzyloxylation. Thus PBLG, PBDG, and PCBLL were first synthesized by the NCA method. The polymerization was carried out at $25^{\circ} \mathrm{C}$ in a $1: 1(\mathrm{v} / \mathrm{v})$ mixture of dioxane and methylene dichloride in the presence of triethylamine (TEA) as an initiator. The numberaverage molecular weight, $M_{n}$, was determined in dimethylformamide at $30^{\circ} \mathrm{C}$ with an Electronic High-Speed Membrane Osmometer (Knauer), in which a regenerated cellulose membrane SD (Sartorius Membran-filter $\mathrm{GmbH}$ ) was used as the semi-permeable membrane.

In Table $I$, the number-average degree of polymerization, $P_{n}$, and the limiting viscosity number $[\eta]$ in dichloroacetic acid (DCA) are given together with the polymerization conditions, the concentration of the NCA, and the mole ratio $[\mathrm{M}] /[\mathrm{I}]$ of the NCA-monomer to the initiator. Debenzylation of PBLG and PBDG was performed at an initial polymer concentration of $0.5 \mathrm{~g} / \mathrm{d} l$ in benzene by blowing hydrogen bromide gas at room temperature. PCBLL dissolved in a $1: 1(\mathrm{v} / \mathrm{v})$ mixture of dioxanechloroform was decarbobenzyloxylated by blowing hydrogen bromide at room temperature. The products obtained by the debenzylation and decarbobenzyloxylation were identified as the expected materials, i.e., PLG, PDG, and PLL, from the elemental analyses and ultraviolet absorption spectra. From the limiting viscosity
Table I. Preparative data of polypeptides

\begin{tabular}{lcrcc}
\hline Sample & $\begin{array}{c}\text { NCA Concn, } \\
\%\end{array}$ & {$[\mathrm{M}] /[\mathrm{I}]$} & $\begin{array}{c}{[\eta],} \\
\mathrm{d} l / \mathrm{g}\end{array}$ & $M_{n}$ \\
\hline PBLG & 3.0 & 250 & 2.02 & 209,000 \\
PBDG & 3.0 & 50 & 1.22 & 146,000 \\
PCBLL & 3.0 & 100 & 2.20 & 238,000 \\
\hline
\end{tabular}

data of PLG, PDG, and PLL in $0.1-N \mathrm{NaCl}$ aqueous solution, it was concluded that no remarkable chain scission occured during the debenzylation or decarbobenzyloxylation.

The degrees of dissociation $\alpha$ of PLG and PLL in the absence of microsalt were determined by potentiometric titrations. The initial concentrations of PLG and PLL were 0.0033M (base-mole) and $0.0073 M$, respectively.

\section{Preparation of Mixtures}

Separate dilute aqueous solutions were prepared for PLG, PDG, and PLL. The PLL solution was adjusted at $\mathrm{pH} 12$ by adding $1.0-\mathrm{N}$ $\mathrm{NaOH}$. The concentrations of these solutions were denoted in terms of the base-moles of the amino acid residues. Mixtures were prepared by slow dropwise addition of an aqueous solution of PLG or PDG at pH ca. 7 to the PLL solution at $\mathrm{pH} \mathrm{12,} \mathrm{and} \mathrm{then} \mathrm{the} \mathrm{pH}$ of the mixtures was brought to the desired values by adding concentrated $\mathrm{HCl}$. The relative proportions of the two components were quoted as the base-mole ratios.

\section{Circular Dichroism and Optical Rotatory Dispersion}

The circular dichroism (CD) and the optical rotatory dispersion (ORD) spectra were measured at $25 \pm 0.5^{\circ} \mathrm{C}$ in the range of wavelength 200 $280 \mathrm{~nm}$, using a JASCO J-20 CD/ORD Spectropolarimeter equipped with a quartz cell of path length 0.5 or $1 \mathrm{~mm}$. The total polymer concentrations in aqueous solutions were from 0.002 to $0.003 M$ with respect to amino acid residues. The concentrations were determined by conductometric titration and/or gravimetry. The residue ellipticity $[\theta]$ and the residue rotation [R] for complex systems were calculated based on the base-mole concentration of the amino acid residue which is capable of existing in $\alpha$ helix conformation at the given $\mathrm{pH}$, i.e., $\mathrm{L}-$ or D-glutamic acid at $\mathrm{pH}$ less than 7, and L-lysine at $\mathrm{pH}$ larger than 7 . 
pH Measurements

The $\mathrm{pH}$ meter used was a Hitachi-Horiba pH-Meter Model F-7 ss $_{\text {ss }}$ equipped with a combination $\mathrm{pH}$ electrode $6028-10 \mathrm{~T}$, the sensitivity of which was $0.005 \mathrm{pH}$. The meter was calibrated with the standard buffer solutions before and after the $C D$ and $O R D$ measurements. The experimental error of $\mathrm{pH}$ values was within $0.02 \mathrm{pH}$ units.

\section{RESULTS AND DISCUSSION}

Conformations of Poly(L-glutamic acid), Poly(Dglutamic acid), and Poly-L-Lysine as Functions of $p H$

The circular dichroism data, expressed as the residue ellipticity $[\theta]$, of PLG, PLL, and PDG at typical $\mathrm{pH}$ values are shown in Figures 1, 2, and 3 , respectively. As revealed by Holzwarth and Doty, ${ }^{14}$ the $\mathrm{CD}$ spectrum of the $\alpha$-helix conformation is characterized with a negative $222 \mathrm{~nm}$ band assigned to the $n \rightarrow \pi^{*}$ transition,

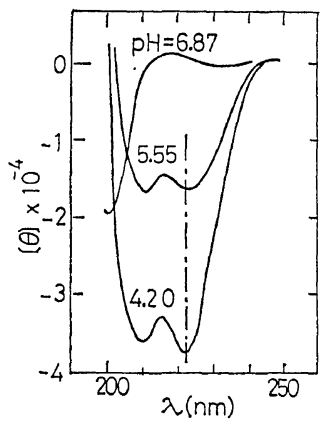

Figure 1. CD spectra of PLG in aqueous solutions at $25^{\circ} \mathrm{C}$ and various $\mathrm{pH}$ values.

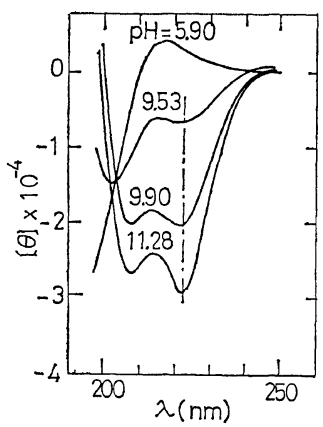

Figure 2. CD spectra of PLL in aqueous solutions at $25^{\circ} \mathrm{C}$ and various $\mathrm{pH}$ values.

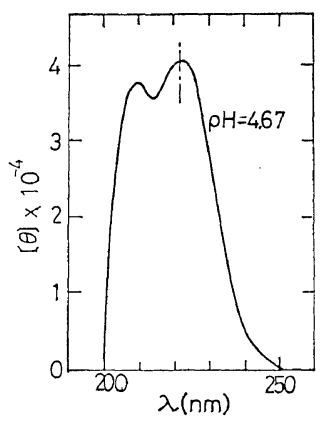

Figure 3. $C D$ spectra of $P D G$ in aqueous solutions at $25^{\circ} \mathrm{C}$ and $\mathrm{pH} 4.67$.

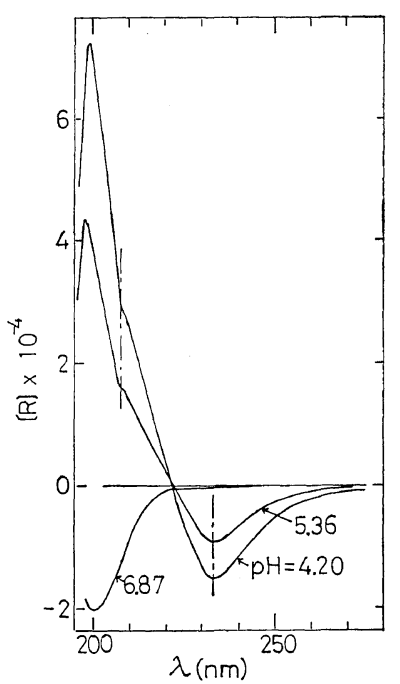

Figure 4. ORD spectra of PLG in aqueous solutions at $25^{\circ} \mathrm{C}$ and various $\mathrm{pH}$ values.

and a positive $190 \mathrm{~nm}$ and a negative $208 \mathrm{~nm}$ band, both assigned to the $\pi \rightarrow \pi^{*}$ transition; the random coil conformation is characterized by a negative $200 \mathrm{~nm}$ Cotton effect. The $\beta$-structure was characterized ${ }^{15}$ by a negative $217 \mathrm{~nm}$ band $([\theta]=-19300)$ and a positive $195 \mathrm{~nm} \cdot([\theta]=$ +28000 ) using PLL. The ORD data for PLG and PLL shown in Figures 4 and 5 are in accord with the results of Holzwarth, et al., ${ }^{14,16}$ and Blout, et al., ${ }^{17}$ and moreover are consistent with the results given in Figures 1 and 2. One can estimate the helical content from $[\theta]_{222}$ at 222 $\mathrm{nm}$ or $[R]_{232}$ at $232 \mathrm{~nm}$, because the $222 \mathrm{~nm}$ band of the CD spectra corresponds to the 232 $\mathrm{nm}$ band of the ORD spectra. 


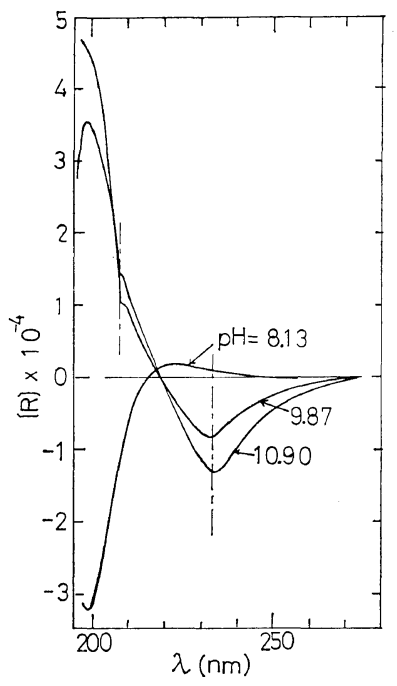

Figure 5. ORD spectra of PLL in aqueous solutions at $25^{\circ} \mathrm{C}$ and various $\mathrm{pH}$ values.

As is obvious from Figures 1 and 2, the 222 $\mathrm{nm}$ trough appears at $\mathrm{pH}=4.20 \sim 5.66$ for $\mathrm{PLG}$ and at $\mathrm{pH}=9.53 \sim 11.28$ for PLL; the depth of the trough depends on $\mathrm{pH}$. The $\mathrm{CD}$ curve of PDG, as shown in Figure 3, is symmetrical to the corresponding curve of PLG with respect to the abscissa. These facts show that PLG and PLL can exist in the right-handed $\alpha$-helix, whereas PDG is in the left-handed $\alpha$-helix. The maximum values of $-[\theta]_{222}$ obtained for PLG, PDG, and PLL are $37500,-40400$, and 30000 , respectively, the value of PLL being considerably smaller than 40000 reported $^{18}$ for a perfect $\alpha$ helix of PLG. It is not known whether the value 30000 obtained for PLL is characteristic of PLL, or whether it originates from the possibility that PLL can not form a perfect $\alpha$-helix. With PLL, the maximum value of $[R]_{232}$ is also smaller than the value assigned for a perfect $\alpha$-helix. The weak positive maximum which appeared at $218 \mathrm{~nm}$ for PLL at pH 5.90 may be understandable, if we assume an extended structure of charged coils ${ }^{19}$ for PLL at this $\mathrm{pH}$.

The $\mathrm{pH}$ dependences of $-[\theta]_{222}$ for PLG and PLL are shown by the broken curves in Figures 11 and 12, respectively. These curves represent the change of helical content against $\mathrm{pH}$, indicating that the PLG exists in $\alpha$-helix at $\mathrm{pH}$ less than 5 and in random coil conformation at $\mathrm{pH}$ higher than 7; the PLL exists in $\alpha$-helix at $\mathrm{pH}$ higher than 11 and in random coil conformation at $\mathrm{pH}$ less than 9 .

Interaction of Poly(L-glutamic acid) with Poly-LLysine, and Its Effects on Chain Conformations

When PLG reacts with PLL in an aqueous solution of a suitable $\mathrm{pH}$, a polyelectrolyte complex linked with salt-bridges, as shown in Figure 6, is formed; the number of such saltbridges is a function of $\mathrm{pH}$.

Figure 7 shows the relations between the degree of dissociation $\alpha$ and the $\mathrm{pH}$ for PLG and PLL. These curves are compared with the helix-coil transition curves of PLG and PLL indicated in Figures 11 and 12. Obviously, both PLG and PLL exist in random coil conforma-

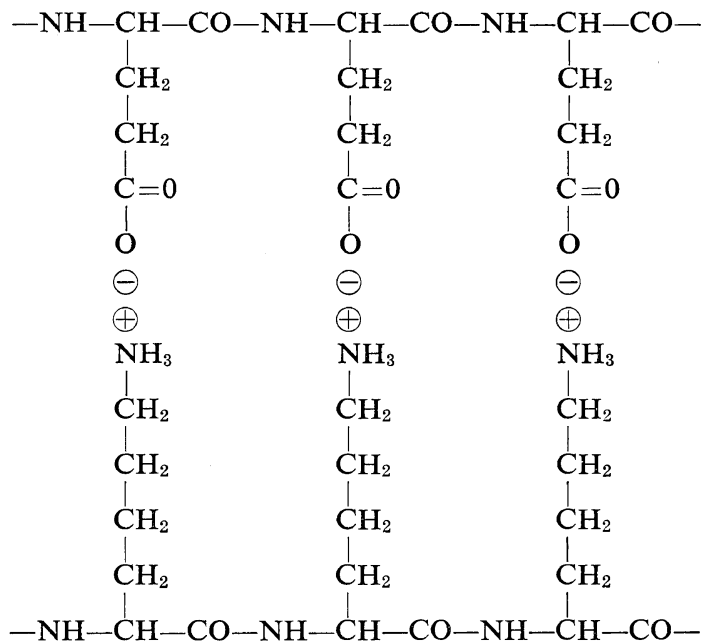

Figure 6. Polyelectrolyte complex formed from poly(glutamic acid) and polylysine.

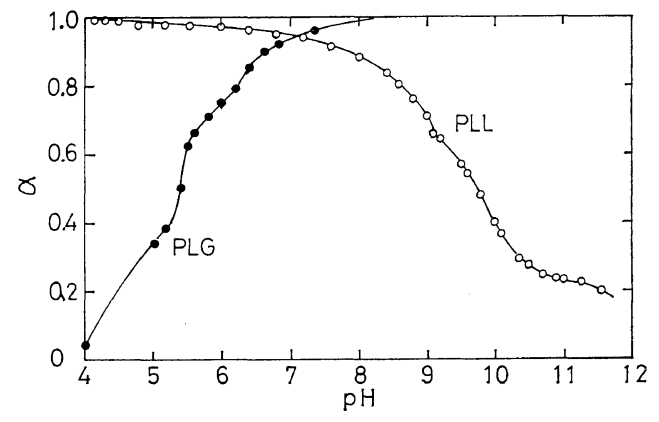

Figure 7. Degree of dissociation $\alpha$ plotted against $\mathrm{pH}$ for PLG and PLL. 


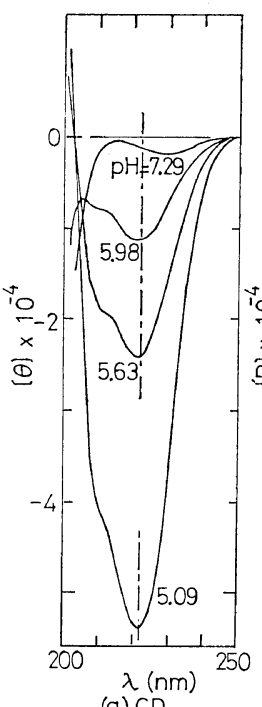

(a) $C D$

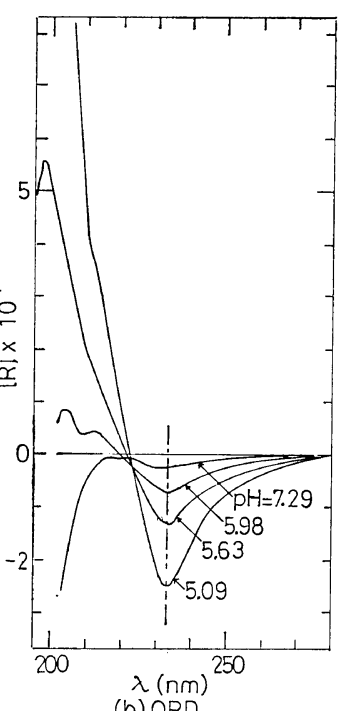

(b) ORD
Figure 8. CD (a) and ORD (b) spectra of $74: 26$ mole ratio PLG-PLL mixture at $25^{\circ} \mathrm{C}$ and various $\mathrm{pH}$ values.

tion when $\alpha$ is close to unity, and transform to $\alpha$-helix conformation with decreasing $\alpha$.

PLG was reacted with PLL in different mole ratios, and the residue ellipticity $[\theta]$ and the residue rotation $[R]$ of the mixtures were measured at different $\mathrm{pH}$ values. Figures $8 \mathrm{a}$ and $b$ are the CD and ORD data of the $74: 26$ mole ratio PLG-PLL mixture. Comparison of Figure 8a with Figure 1 leads to the following characteristic differences between the CD spectra of the PLG-PLL mixture and of PLG: (a) No shift of wavelength is observed for the negative Cotton effect at $222 \mathrm{~nm}$ at $\mathrm{pH}$ 's lower than about 6, while the depth of $[\theta]_{222}$ of the PLGPLL mixture at $\mathrm{pH}$ lower than 5 is considerably larger than that of PLG. (b) The negative Cotton effect at $208 \mathrm{~nm}$ assigned to the $\pi \rightarrow \pi^{*}$ transition appears as a shoulder for the PLGPLL mixture in contrast to the trough which appeared for PLG. The numerical values of $[\theta]_{208}$ for the PLG-PLL mixture at different $\mathrm{pH}$ 's are almost the same as those of PLG at corresponding pH's. (c) At pH 7.29, however, the negative $222 \mathrm{~nm}$ band shifts to a slightly longer wavelength and the shoulder at $208 \mathrm{~nm}$ disappears. The $\pi \rightarrow \pi^{*}$ transition originates mainly from the main chain structure, while the $n \rightarrow \pi^{*}$ transition originates from the relative conformation of the side chain residue to the peptide plane. The experimental facts (a) and (b) may indicate that the $222 \mathrm{~nm}$ band $\left(n \rightarrow \pi^{*}\right)$ is important for conformational investigations of polymer complexes formed by the salt-bridges between oppositely charged side chain residues. Comparison of Figure 8b with Figure 4 leads to the same conclusion with respect to the ORD spectra as that for the $\mathrm{CD}$ spectra, i.e., the numerical value of $[R]_{232}$ of the PLG-PLL mixture is considerably larger than that of PLG, and the location of this band is unchanged.

Generally speaking, the ORD spectra are sensitive to the turbidity of the solutions, while the CD spectra are less sensitive. The PLGPLL mixtures examined here are slightly or weakly turbid. But such an extent of turbidity may hardly affect the CD and ORD spectra, because of the fact that the helical content estimated from the ORD data coincides with that from the $\mathrm{CD}$ data for the mixtures.

The CD spectra of the $56: 44$ mole ratio PLG-PLL mixture and the 18:82 mole ratio PLG-PLL mixture are shown in Figures 9 and 10 , respectively, in which $[\theta]$ 's at $\mathrm{pH}$ 's below 7 and above 8 are based on the concentrations of PLG and PLL, respectively. At pH's below 7 , the negative Cotton effect assigned to $n \rightarrow \pi^{*}$ transition appears correctly at $222 \mathrm{~nm}$, but at pH's above 9, a negative band appears at 217 $\mathrm{nm}$ for both the $56: 44$ mole ratio PLG-PLL, and the 18:82 mole ratio PLG-PLL mixture. Further, the trough or shoulder at $208 \mathrm{~nm}$ is

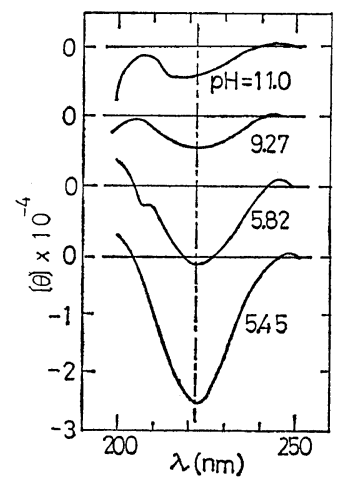

Figure 9. CD spectra of $56: 44$ mole ratio PLGPLL mixture at $25^{\circ} \mathrm{C}$ and various $\mathrm{pH}$ values. 


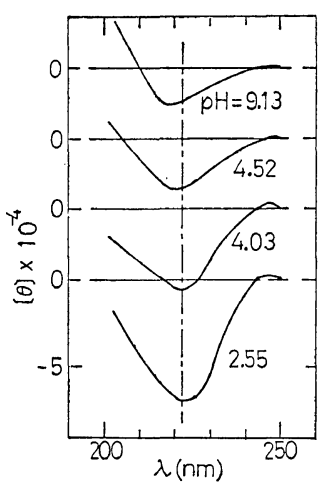

Figure 10. CD spectra of $18: 82$ mole ratio PLGPLL mixture at $25^{\circ} \mathrm{C}$ and various $\mathrm{pH}$ values.

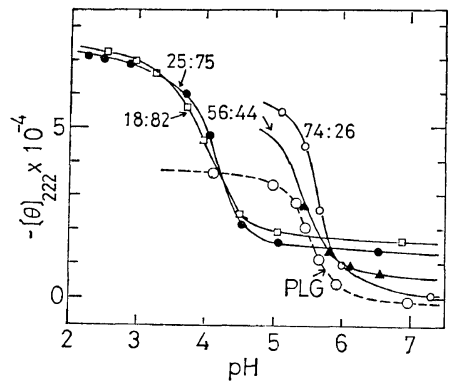

Figure 11. $-[\theta]_{222}$ plotted against $\mathrm{pH}$ for $74: 26$ (○), $56: 44(\mathbf{A}), 25: 75(\bullet)$, and $18: 82(\square)$ mole ratio PLG-PLL mixtures, and for PLG (broken curve) at $\mathrm{pH}$ 's below 7.5.

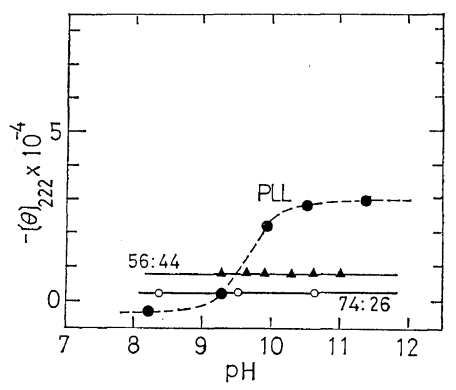

Figure 12. $-[\theta]_{222}$ plotted against $\mathrm{pH}$ for $74: 26$ (O) and 56:44 (ム) mole ratio PLG-PLL mixtures, and for PLL (broken curve) at pH's above 8.

difficult to distinguish, except for one instance ( $\mathrm{pH}$ 5.82, Figure 9). The characteristic features of these curves are that the numerical values of $[\theta]_{222}$ of the mixture at $\mathrm{pH}$ less than 7 are markedly larger than those of PLG at corre- sponding $\mathrm{pH}$ 's, whereas the $[\theta]_{222}$ 's at $\mathrm{pH}$ 's higher than 9 are smaller than those of PLL and, moreover, almost constant independent of $\mathrm{pH}$.

In Figures 11 and $12,-[\theta]_{222}$ of PLG-PLL mixtures is plotted against $\mathrm{pH}$, in which data not shown in previous figures are also included. If the salt formation between $\mathrm{COO}^{-}$of PLG and $\mathrm{NH}_{3}^{+}$of PLL proceeds stoichiometrically, then the composition of the polyelectrolyte complexes, given by the base-mole fraction, is obtained from Figure 7 as a function of $\mathrm{pH}$, as shown in Figure 13. As is obvious from Figure 11, at PLG-to-PLL mole ratios higher than 1, the $\mathrm{pH}$ 's at the midpoint of the transition curves do not significantly differ from that of PLG, while the numerical values of $-[\theta]_{222}$ of the mixtures are higher than those of PLG over the whole $\mathrm{pH}$ range. This result may indicate that the helix formation of PLG is not greatly affected, but the helix formation of PLG is supported by the presence of small amount of PLL. With decreasing PLG-to-PLL mole ratios, the $\mathrm{pH}$ 's at the midpoint of the transition shift toward lower $\mathrm{pH}$ values, and, at the same time, $-[\theta]_{222} v s . \mathrm{pH}$ curves of the mixtures shift upward compared with that of PLG. The $-[\theta]_{222}$ of the mixtures at sufficiently low $\mathrm{pH}(2 \sim 3)$ are about twice as much as that of PLG, and the $-[\theta]_{222}$ at $\mathrm{pH}$ about 7 is about 20000 , which is considerably higher than the value $(\sim 0)$ assigned to the random coil conformation. The shift of $\mathrm{pH}$ at the midpoint toward lower $\mathrm{pH}$ may imply that the presence of a large amount of PLL rela-

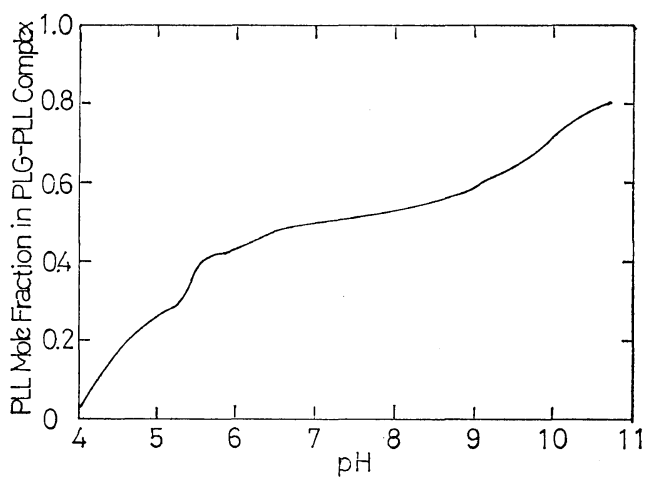

Figure 13. Mole fraction of PLL in stoichiometric PLG-PLL complex as a function of $\mathrm{pH}$. 
tive to PLG acts as to suppress helix formation.

As is obvious from Figure 7, at pH's lower than 4 , most of the carboxyl groups of PLG are not protonated and the chain is in an $\alpha$-helix conformation, while PLL is in a random coil conformation at close to unity. The results shown in Figure 11 may also indicate that the PLL molecules surround the core of the righthanded $\alpha$-helix of PLG in this $\mathrm{pH}$ region. This conclusion is different from that of Hammes and Schullery, ${ }^{13}$ their experiments were carried out in aqueous $0.01-M \mathrm{NaF}$ in contrast to our experiments, which were done in the absence of added microsalt.

At $\mathrm{pH} 7$, on the other hand, both PLG and PLL by themselves are sufficiently ionized (see Figure 7) and they are in the random coil conformation. The CD spectra in Figure 11 at $\mathrm{pH}$ about 7 may indicate that, when the PLG-toPLL mole ratio is large, chains are nearly in a random coil conformation, while when the mole ratio of PLG is small, the chains are in a less disordered conformation, though a quantitative explanation is not possible. The polyelectrolyte complex (aggregation) formed in this case may be in a scramble-salt form. It is difficult to concluded that the aggregation at $\mathrm{pH} 7$ is in the $\beta$-conformation as suggested by Hammes and Schullery. ${ }^{13}$

The CD spectra at pH's higher than 8 are shown in Figure 12. The $-[\theta]_{222}$ values of the $74: 26$ mole ratio PLG-PLL mixture and of the $56: 44$ mole ratio PLG-PLL mixture are respectively independent of $\mathrm{pH}$. Even in the $\mathrm{pH}$ region where the PLL by itself exists in an $\alpha$-helix conformation, the $-[\theta]_{222}$ values of the mixtures are much smaller than those of PLL. This fact may indicate that the presence of PLG acts as to suppress the helix formation of the PLL. In this $\mathrm{pH}$ range, PLG is sufficiently dissociated, while PLL dissociates as a function of $\mathrm{pH}$ (see Figure 7). As noted in Figures 9 and 10 , the CD spectra of PLG-PLL at high $\mathrm{pH}$ exhibit a small trough at $217 \mathrm{~nm}$. Presumably the PLG-PLL complexes are in a form close to the $\beta$-structure at this $\mathrm{pH}$ region. This conclusion also is not in accord with that of Hammes and Schullery, ${ }^{13}$ who reported that no interaction was detected in PLG-PLL mixture at $\mathrm{pH} 11$.
Conformation Effect of Poly(D-glutamic acid) to Poly-L-Lysine

The effects of D-polypeptide, which is able to form a left-handed $\alpha$-helix, on L-polypeptide having an opposite charge were examined with ca. 60:40 mole ratio PDG-PLL mixtures at typical pH's, i.e., pH 2.5 and $\mathrm{pH} 12.0$, at which PDG and PLL by themselves exist in left- and right-handed $\alpha$-helices, respectively. The CD spectra obtained are given in Figures 14 and 15. At $\mathrm{pH} 2.5$, a positive peak appears at $222 \mathrm{~nm}$, and the band assigned to the $\pi \rightarrow \pi^{*}$ transition is observed as a positive shoulder at $208 \mathrm{~nm}$ for the PDG-PLL. The general features of the curve are the same as those for the PLG-PLL mixture under corresponding conditions, except that the sign of $[\theta]$ values is reversed, but a marked difference between the PDG-PLL mixture and the corresponding PLG-PLL mixture is that the absolute value of $[\theta]_{222}$ of the PDG-

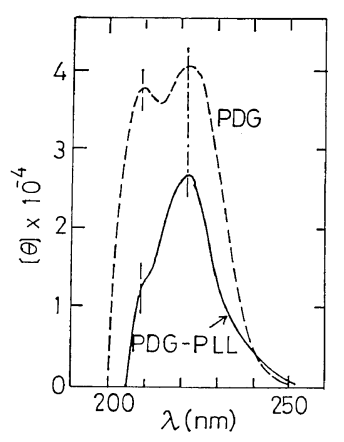

Figure 14. CD spectra of $53: 47$ mole ratio PDGPLL mixture at $\mathrm{pH} 2.50$ and of PDG (broken curve) at $\mathrm{pH} 4.76$.

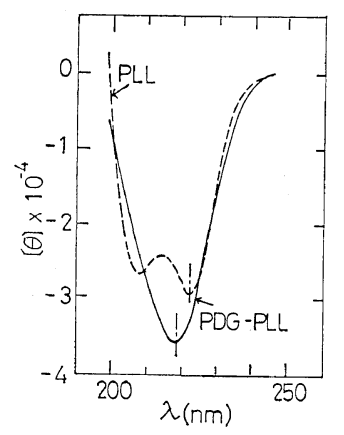

Figure 15. CD spectra of $60: 40$ mole ratio PDGPLL mixture at $\mathrm{pH} 12.02$ and of PLL (broken curve) at $\mathrm{pH} 11.00$. 
PLL mixture is smaller than that of PDG, in contrast to the case of the PLG-PLL mixture, in which the absolute value of $[\theta]_{222}$ was markedly larger than that of PLG. This fact may imply that helix formation of PDG is greatly disturbed by the presence of PLL.

On the other hand, at $\mathrm{pH} 12$ where PLL by itself can form an $\alpha$-helix, only a negative band is detected at $218 \mathrm{~nm}$ for the PDG-PLL mixture. This fact strongly supports the presence of a scramble-salt type aggregate composed of $\beta$-structures.

The results obtained in this paper lead to the important conclusion that the interactions between two oppositely charged polypeptides, together with the conformation of complexes formed, are not only influenced by $\mathrm{pH}$ but also markedly affected by the combination of helical senses of the partner polymers. An acidic Dpolypeptide interacts with a basic L-polypeptide in a quite different way from an acidic L-polypeptide interacting with a basic L-polypeptide.

\section{REFERENCES}

1. H. G. Bungenberg de Jong, "Colloid Science," Vol. 2, H. R. Kruyt, Ed., Elsevier, Amsterdam, 1949.

2. A. Nakajima and H. Sato, Biopolymers, 11, 1345 (1972).

3. H. Sato and A. Nakajima, Colloid \& Polymer Sci., 252, 294, 944 (1974).

4. A. Nakajima and H. Sato, Bull. Inst. Chem.
Res., Kyoto Univ., 52, 664 (1974).

5. H. Sato and A. Nakajima, Polymer J., 7, 257 (1975).

6. R. A. Gelman, W. B. Rippon, and J. Blackwell, Biopolymers, 12, 54 (1973).

7. R. A. Gelman, D. N. Glaser, and J. Blackwell, ibid., 12, 1223 (1973).

8. R. A. Gelman and J. Blackwell, ibid., 12, 1959 (1973).

9. R. A. Gelman and J. Blackwell, ibid., 13, 139 (1974).

10. W. B. Gratzer and P. McPhie, ibid., 4, 601 (1966).

11. A. B. Zezin, V. V. Lutsenko, V. B. Rogacheva, O. A. Aleksina, R. I. Kalyuzhnaya, V. A. Kabanov, and V.A. Kargin, Vysokomol. Soedin., A14(4), 772 (1972).

12. J. Noguchi, T. Saito, T. Hayakawa, H. Kokuyama, and T. Harada, Nippon Kagaku Zasshi (J. Chem. Soc. Japan, Pure Chem. Sect.), 82, 597 (1961).

13. G. G. Hammes and S. E. Schullery, Biochemistry, 7, 3882 (1968).

14. G. Holzwarth and P. Doty, J. Amer. Chem. Soc., 87, 218 (1965).

15. B. Davidson, N. Tooney, and G. D. Fasman, Biochem. Biophys. Res. Commun., 23, 156 (1966).

16. G. Holtzwarth, W. B. Gratzer, and P. Doty, J. Amer. Chem. Soc., 84, 3194 (1962).

17. E. R. Blout, I. Schmier, and N.S. Simmons, ibid., 84, 3193 (1962).

18. E. Iizuka and J. Yang, Proc. Nat. Acad. Sci. U.S., 55, 1175 (1966).

19. M. L. Tiffany and S. Krimm, Biopolymers, 8 , 347 (1969); 11, 2309 (1972); 12, 575 (1973). 